\title{
Advantages and Limitations of Endoscopic Septoplasty: Experience of 120 Cases
}

\author{
${ }^{1}$ Md. Ashraful Islam MBBS, FCPS, \\ FICS, FRCS (Glasgow), \\ Professor and Head, Otolaryngology- \\ Head \& Neck Surgery, Bangladesh \\ Medical College Hospital \\ ${ }^{4}$ Towsif Bin Mamoon, MBBS, \\ Assistant Registrar, ENT, \\ Bangladesh Medical College \\ Hospital
}

\author{
${ }^{2}$ Tareq Mohammad MBBS, FCPS, \\ Assistant Registrar ENT, Bangladesh \\ Medical College Hospital
}

${ }^{5}$ Farid Uddin Milki, MBBS, DLO Consultant ENT, Bangladesh Medical College Hospital

\author{
${ }^{3}$ Nazmul Hossain Chowdhury, \\ MBBS, FCPS, \\ Assistant Professor, ENT, \\ Bangladesh Medical College \\ Hospital \\ ${ }^{6}$ ASM Lutfur Rahman MBBS, \\ MCPS, DLO, MRCPS (Glasgow), \\ Resident Surgeon, Bangladesh \\ Medical College Hospital
}

Abstract:

\section{Objective:}

Traditional surgeries for the deviated nasal septum improves the nasal airway but recent development and advancement of the knowledge about endoscope has changed the treatment modality significantly. Endoscopic approach under good Illumination and magnification lessen the complication. This study is done to see the advantages and limitations of endoscopic septoplasty

\section{Method:}

Total 120 cases of symptomatic deviated nasal septum, refractory to conservative medical treatment were randomly selected on the basis of clinical examination in a single institute. It was a prospective study, performed to see the advantages and limitations of endoscopic septoplasty. Informed written consent was taken in all cases. All the patients underwent endoscopic septoplasty under general anesthesia after proper evaluation.

\section{Results:}

There was a slight male predominance. 13 year child was the youngest patient and 58 was the oldest. During endoscopic septoplasty a large number of patients needed some additional surgery like, inferior turbinoplasty in $27(22.5 \%)$, functional endoscopic sinus surgery in 11 patients $(9.16 \%)$ etc. The complication rate was minimum $(4.16 \%)$. Patient's satisfaction was high. Though there were some limitations but we observed so many advantages of this procedure.

\section{Conclusion:}

Though conventional Septoplasty is widely practiced by most ENT surgeons till now, the endoscopic approach can be considered as a better alternative.

Keywords:- Advantages, Deviated Nasal Septum, Endoscopic Septoplasty.

\section{INTRODUCTION}

Nasal obstruction is one of the most common complain that an otolaryngologist faces on day to day practice Deviated nasal septum is the most common problem behind this. It not only causes breathing difficulty but also causes impaired aeration to the paranasal sinuses and causes recurrent infection to the paranasal sinuses ${ }^{1}$ .Various techniques have been proposed for the correction of the different types of septal deviations in the past. The concept of submucosal resection was popularized and refined by Killian ${ }^{2}$ and Freer $^{3}$ separately in the early twenties. Later Septoplasty was introduced with less and required excision of deviated portion only, where the surgery is to be done with the help of headlight, but it is a selfish surgery where the assistant can't see the field and the structures to be resected ${ }^{5}$. In this traditional septal surgery there is often over exposure, unnecessary manipulation of the septal anatomy by a large incision and by elevation of flaps on both sides of nasal septum ${ }^{18}$.The advent of endoscope has revolutionized rhinology and has widened the horizon of rhinology. Lanza et al and Stammberger initially described the application of endoscopic technique for the correction of septal deformity in $1991^{5,13}$.Furthermore in complex deformities, better correction is possible with the help of an endoscope since we can see the posterior deviation clearly. Endoscope also aided limited resection and thus more conservation by guiding precise shaving of septal cartilage ${ }^{5}$.

$>$ Objectives of the study:

- General: .To justify the efficacy of endoscopic septoplasty procedure and its complications.

- Specific:

$\checkmark$ To establish a best teaching and learning tool for septal surgery

$\checkmark$ To establish a best surgical procedure for posterior septal deviation.

Study design:

A simple random prospective interventional study. 
> Place of study: Dhaka

Bangladesh Medical College Hospital, Dhanmondi.

\section{Duration of study:}

Jan 2016 to July 2018

\section{> Sampling Method:}

Among all consecutive admitted cases in ENT ward of Bangladesh Medical College hospital with Symptomatic DNS, 120 patients were randomly selected for endoscopic septoplasty within the study period. All the selected patients were evaluated with detailed history, clinical examination and proper investigations. After taking an informed written consent, all patients were operated under general anesthesia. Data were recorded and complied in a structured data sheet and data were analyzed.

\section{$>$ Selection Criteria}

- Inclusion criteria:

$\checkmark$ Patients with symptomatic deviated nasal septum/ septal spur, refractory to conservative treatment.

- Exclusion criteria:

$\checkmark$ Medically unfit for surgery

$\checkmark$ Refusal to accept this procedure

Surgical equipment:

- All conventional instruments for septoplasty

- $0^{0}$ and $70^{\circ}$ telescope

- Camera

- Monitor

\section{RESULTS}

Among all patients, the youngest patient was 13 year old and the oldest was 58 year old. In that patients, most common age group is 21-30 years (36.67\%) (Table-1). There was a slight male predominance with a ratio of 1.86:1(table-2).

Among all patients, nasal obstruction was main symptom and others were associated problem in most of cases. Out of 120 patients, 112 patients (93.33\%) had presented with nasal obstruction. The next common associated symptom was headache in 52 patients $(43.33 \%)$, dry mouth $16.67 \%$, and epistaxis $6.67 \%$ (table- 3 ).

All patients with symptomatic deviated nasal septum were clinically examined before and after admission. Among them only deviated nasal septum (DNS) was the most common finding 55 patients (45.83\%). The next common was DNS with Hypertrophied inferior turbinate, found in 37 patients $(30.83 \%)$ and the next feature was an isolated septal spur in $23.3 \%$ cases. (Table 4). Others are hyposmia, snoring etc.

During surgical procedure only endoscopic septoplasty (ES) was done in $59(49.26 \%)$ cases, rest of cases was a combination procedure such as: ES with inferior turbinoplasty in $27(22.5 \%, \quad)$, ES with conchoplasty in $9(7.5 \%)$ cases, septoplasty with functional endoscopic sinus surgery in 11( $9.16 \%)$ patients, submucosal diathermy done in 10 cases $(8.33 \%)$ (Table 5).

In our study of 120 cases, immediate complications happened in 5 patients $(4.16 \%)$. Among them undue haemorrhage from septal branch of superior labial artery in $2(1.66 \%)$ cases, that was slightly unusual and happened during removal of maxillary crest and unilateral flap tear in $3(2.5 \%)$ cases though all of these was very minor complication and easily manageable. (Table 6)

All patients were discharged on $1^{\text {st }}$ POD after removal of nasal pack. All were given the following advices:

$>$ Nasal douching with warm saline for 15 days

$>$ To wear face mask on outgoing for 15 days

$>$ Avoidance of forceful nasal blowing for 15 days

$>$ Follow-up on $7^{\text {th }}$ POD for splint removal, after 1 month and then $6^{\text {th }}$ months or telephonic.

All patients were examined on $7^{\text {th }}$ POD, after 1 month and $6^{\text {th }}$ month. All were examined in Operation theater with $0^{\circ}$ and $70^{\circ}$ telescope, especially for cleaning of crust and additional examination of Sinuses in FESS cases. We did not observed any case of persistent lateral wall or septal pathology and anatomical deformity. There was an improved nasal airway in all cases.

At the end of our study we observed the following Advantages of endoscopic septoplasty:

$>$ Excellent illumination

$>$ Adequate limited exposure

$>$ Highly specific for high deviation and posterior septal spur

Highly specific for limited septoplasty

$>$ Very low per and postoperative complications

$>$ Additional paranasal surgeries can be done if required

$>$ Excellent teaching tool specially for under graduate students and post graduate trainees

$>$ Meticulous flap elevation can be a training tool for future anterior skull base reconstruction

$>$ Higher satisfaction by the patients and their attendants

$>$ Less hospital stay

Limitations:

Adequate additional training

$>$ Higher cost of instruments endoscope, camera, telescope, monitor etc

$>$ Higher cost of surgeries 
ISSN No:-2456-2165

\begin{tabular}{|c|c|c|}
\hline Age distribution & No. of patients in Endoscopic septoplasty group & Percentage \% \\
\hline $0-10$ & 0 & 0 \\
\hline $11-20$ & 40 & 33.33 \\
\hline $21-30$ & 44 & 36.67 \\
\hline $31-40$ & 20 & 16.67 \\
\hline $41-50$ & 12 & 10 \\
\hline $51-60$ & 4 & 3.33 \\
\hline
\end{tabular}

Table 1:- Age distribution (inclusive) $(\mathrm{n}=120)$

Sex Distribution: $(\mathrm{n}=120)$ (table 2)

\begin{tabular}{|c|c|c|}
\hline Sex & No. of patients in Endoscopic septoplasty group & Percentage\% \\
\hline Male & 80 & 66.67 \\
\hline Female & 40 & 33.33 \\
\hline
\end{tabular}

Table 2

Symptomatology: $(\mathrm{n}=120)$ ( table 3$)$

\begin{tabular}{|c|c|c|}
\hline Symptoms & No. of patients in Endoscopic septoplasty & Percentage\% \\
\hline Nasal obstruction & 112 & 93.33 \\
\hline Headache & 52 & 43.33 \\
\hline Snoring & 16 & 13.33 \\
\hline Dry mouth & 20 & 16.67 \\
\hline Nasal bleeding & 8 & 6.67 \\
\hline Reduced smell sense & 8 & 6.67 \\
\hline
\end{tabular}

Table 3

Anterior Rhinoscopy Findings (table 4)

\begin{tabular}{|c|c|c|}
\hline Finding & No of patients & Percentage \% \\
\hline DNS & 55 & 45.83 \\
\hline Septal Spur & 28 & 23.33 \\
\hline DNS with Hypertrophied IT & 37 & 30.83 \\
\hline
\end{tabular}

Table 4

Types of Surgical Intervention n=120_(table 5)

\begin{tabular}{|c|c|c|}
\hline Surgical procedures & No of cases & Percentage\% \\
\hline Endoscopic septoplasty (ES) & 59 & 49.16 \\
\hline ES with FESS & 11 & 9.16 \\
\hline ES with Partial inferior turbinectomy & 4 & 3.33 \\
\hline ES with conchoplasty & 9 & 7.5 \\
\hline ES with inferior turbinoplasty & 27 & 22.5 \\
\hline ES with SMD & 10 & 8.33 \\
\hline
\end{tabular}

Table 5 
Per-operative and post-operative complications (Table 6):

\begin{tabular}{|c|c|c|c|}
\hline \multirow{2}{*}{ Complications } & \multicolumn{2}{|c|}{ Endoscopic septoplasty } & Percentage \% \\
\cline { 2 - 4 } & Immediate & late & 1.66 \\
\hline Excessive hemorrhage & 2 & 0 & \\
\hline Septal perforation & 0 & 0 & \\
\hline Synechiae & 0 & 0 & \\
\hline External deformity & 0 & 0 & \\
\hline Hematoma & 0 & & \\
\hline Flap tear & 3 & & \\
\hline
\end{tabular}

Table 6

\section{DISCUSSION}

Nasal obstruction due to deviated nasal septum is a common problem encountered by otolaryngologist 1 . To relieve this nasal obstruction septoplasty is the commonly performed surgical procedure10.In traditional head light based septal surgery there is poor illumination and less accessibility to posterior septum leads to over exposure, unnecessary manipulation of septal anatomy and more resection 18. The advent of endoscope has revolutionized rhinology and has widened the horizon of rhinology11. The nasal endoscope allows precise preoperative identification of the septal pathology and its associated lateral nasal wall abnormalities and helps in better planning of endoscopic aided septal surgery10. Endoscopic septoplasty is a directed septoplasty and an effective technique that can be performed safely alone or in combination with endoscopic sinus surgery / endoscopic DCR etc11. This procedure provides very good Illumination and easy approach to posterior bony spur and an excellent teaching tool5,11. Till date several studies have been conducted to establish these ideas and the results of maximum studies are similar.

In several studies ${ }^{13,15}$ the most common age group belongs to $2^{\text {nd }}$ and $3^{\text {rd }}$ decades. In this study, most common belongs to $3^{\text {rd }}$ decade (table -1 ) that is in concordance with above studies. Krisna et al reported a male preponderance in the comparative study of conventional versus endoscopic septoplasty, ${ }^{15}$ that is in concurrence with our study, where there is a male female ratio of 1.86:1(table -2). There are many studies ${ }^{12,13}$, where nasal obstruction is the most common complain followed by headache, post nasal drip, dryness of mouth, epistaxis, hyposmia etc. In our study of 120 cases, 112 patients $(93.33 \%)$ had presented with nasal obstruction. The next common associated symptom was headache in 52 patients $(43.33 \%)$, dryness of mouth was present in 20 patients (16.67\%), Hyposmia was present in 8 patients $(6.67 \%)$, and epistaxis in 8 patients $(6.67 \%)$ (Table-3). These are consistent to above mentioned studies.

Nayak et al reported that several lateral nasal wall pathologies are associated with deviated nasal septum, the commonest and almost consistent being the inferior turbinate hypertrophy, followed by concha bullosa, paradoxical Middle turbinate, polypoidal middle and inferior turbinate ${ }^{9}$. In the present study we found almost similar findings, commonest being inferior turbinate hypertrophy 37 patients $(30.83 \%)$ followed by septal spur in $28(23.33 \%)$ patients (table -4$)$., that is nearly similar with the study of Mirza et aland Nayak et al ${ }^{9,11)}$ in this regard our drawback was that we didn't preoperatively examined these patients by nasoendoscope due to limited resource in OPD.

Mahlon et al in a retrospective review of 100 patients observed that Endoscopic Septoplasty was performed in 81 patients $(81 \%)$, FESS was performed in $43(43 \%)$ patients, bilateral inferior turbinoplasty in $15(15 \%)$ patients, and partial middle turbinoplasty in $20(20 \%)$ patients. Leena jain et al mentioned on the comparative study of conventional and endoscopic Septoplasty, that out of 50 endoscopic Septoplasty, $20(40 \%)$ underwent this in conjunction with FESS. In our study of endoscopic septoplasty, Solo endo septoplasty was done in 59 $(49.26 \%)$ cases, rest of cases was a combination procedure such as: ES with inferior turbinoplasty in $27(22.5 \%$,$) , ES$ with conchoplasty in $9(7.5 \%)$ cases, septoplasty with functional endoscopic sinus surgery in 11( 9.16\%) patients, submucosal diathermy done in 10 cases (8.33\%) (table:5).That is also comparable to the study of Mirza Aneesa et al, Mahlon et al and Leena $\mathbf{J}$ et $\mathrm{al}^{(19,12,20)}$.

In our study, post operatively ANS pack given in all patients. In Endoscopic septoplasty group ANS pack was removed on $1^{\text {st }}$ POD and were discharged on $1^{\text {st }} P O D$. So it concludes that, there is less hospital stay in endoscopic group in comparison to conventional group. My studyIs in concurrence with the study of Krishna $\mathrm{K} \mathrm{T}^{15}$ and Gupta $\mathrm{M}^{18}$

D.C.Sathyaki et al mentioned in his comparative study, that they examined all patients by $0^{\circ}$ endoscope during post-operative follow-up and noted no persistent deviation or spur in both groups. Persistence of hypertrophy of turbinates' on 3 patients out of 11 in conventional group and 1 in 12 of endoscopic group ${ }^{1}$.Iin our cases all patients were examined on $7^{\text {th }}$ POD, after 1 month and $6^{\text {th }}$ month. All were examined with $0^{\circ}$ and $70^{\circ}$ telescope, especially for cleaning of crusting and additional examination of Sinuses in FESS cases. We did not observed any case of persistent lateral wall or septal pathology. There was improved nasal airway, no anatomical deformity and most importantly we noted very minimum crusting in all cases. It also shows 
some similarity to the literature review done by $\mathrm{C}$. Champagne et $\mathrm{al}^{21}$.

In the study of Sandeep K, Siddhartha $\mathrm{V}^{4}$ noticed, 2 out of $30(6.67 \%)$ patient had residual deviation in conventional group but none in endoscopic group. There was no posterior deviation in endoscopic group but it was 1 in $30(3.33 \%)$ in conventional group, they found septal perforation in 2 (6.67\%)patients out of 30.They observed mucosal tear in $3(10 \%)$ patients in conventional group and $2(6.67 \%)$ in endoscopic group. In this current study, immediate per operative complications happened in 5 patients (4.16\%) among them, undue haemorrhage from septal branch of superior labial artery in 2 (1.66\%)cases that was slightly unusual and happened during removal of maxillary crest, and flap tear in $3(2.5 \%)$ cases though all of these was very minor complication and easily manageable. We did not observed any case of septal perforation, synechia in our cases. That is comparable to the study of Park $\mathrm{DH}^{9}$ et al and $\mathrm{R}$ Bothra et $\mathrm{al}^{17}$.

Several authors mentioned in their studies that endoscopic septoplasty is more advantageous than conventional septoplasty in regarding illumination, unnecessary tissue handling, flap tear, septal perforation rate etc ${ }^{(14,15,16)}$. Throughout our study we also found that, endoscopic septoplasty allows limited incision and limited elevation of the flaps that allows adequate exposure of the pathological site. Due to limited extent of flap dissection along with limited manipulation and resection of septal framework, it reduces the chance of synechiae formation. There is less flap tear in comparison with conventional group. The most important thing in endoscopic septoplasty is, as it done under direct visualization on monitor, it played important rule to improve the learning curve of the trainees commented by many authors in their studies, ${ }^{5,11}$. At the end of our study we also feel that it can play an important rule to improve the learning curve and surgical skill of the trainees significantly,we also feel that meticulous flap elevation under endoscopic guidance can be a training tool for future anterior skull base reconstruction.

The limitations we noted during our study are following: Adequate additional training, higher cost of instruments (endoscope, camera, telescope, monitor etc), higher cost of surgeries (varies upon institutes. Though in our institute it requires only 150 USD in general ward patients.)

\section{CONCLUSION}

Endoscopic septoplasty specifically helpful in dealing with posterior deviations, high deviations, Sinus pathology, isolated spurs, etc. on the same setting. So, a full house sino-nasal surgery can be done with the aid of endoscope if required. Though there are some limitations of endoscopic septoplasty procedure but it can be easily overcome in an Academic Institute. It can improve the learning curve of the trainees significantly which can't be properly done during conventional septoplasty. We would recommened to use $0^{0}$ and $70^{\circ}$ nasoendoscope in every nasal procedure to improve expertise. Last but not the least, Endoscopic septoplasty can be an excellent training tool for future endonasal anterior skull base reconstruction procedure.

\section{REFERENCES}

[1]. D.C. Sathyki, Chyre geera, G.B. Munishwara, M. mohan. A comparative study of endoscopic septoplasty versus Conventional septoplasty. Indian j of otolaryngology \& head neck surg 2014 jun 66(2):155-161

[2]. Killian, G., 1904. Die submucose Fensterresektion der Nasenscheidewand. Archiv fur Laryngologie und Rhinologie, 16: 362.

[3]. Freer, O., 1902. The correction of deflections of the nasal septum with a minimum of traumation. J. of the American Medical Association, 38: 636.

[4]. Sandeep Kaushik, Siddhart Vashistha, Nitin Kumar jain. Endoscopic Vs Conventional septoplasty. 10.5005/jp-journals-10013-1159

[5]. Gupta N. endoscopic septoplasty. Indian j otolaryngology and head neck surgery 2005 Jul;57(3):240-243

[6]. Adriaan F Van Olphen. The Septum. $7^{\text {th }}$ edition, Scott Brown's otolaryngology and Head Neck Surgery.123,P-1570

[7]. H Stammberger And Valerie J Lund. Anatomy of the nose and paranasal sinuses. $7^{\text {th }}$ edition, Scott Brown's otolaryngology and Head Neck Surgery. 104, P-1327.

[8]. Park DH, Kim TM, Han DG, Ahn KY. Endoscopicassisted correction of deviated nose. Aesthetic Plast Surg. 1998;22:190-195. $10.1007 / \mathrm{s} 002669900190$.

[9]. Nayak DR, Balakrishnan R, Murthy KD. An endoscopic approach to the deviated nasal septum-a preliminary study. J Laryngol Otol. 1998;112:934939. doi: 10.1017/S0022215100142124

[10]. Magdy A, Salma. , Endoscopic Aided Septoplasty Versus conventionall Septoplasty, World j of medical science 11 (1) : 33-38,2014.

[11]. Mirza A. A. B, Sajad M, Q, Irfan I. Endoscopic Septoplasty: A Prospsective Analysis. Open Science journal of clinical medicine. Vol 3, No-6,2015,pp 212-219

[12]. SS Suligavi, MK Darade, BD Guttigoli; Endoscopic septoplasty; Advantage And Disadvantages, Clinical Rhinology. An international journal , January-April 2010;3(1)27-30.

[13]. Manjunath R, Chitradurga SV. Is Endoscopic Septoplasty really superior than Conventional Septoplasty? National journal of otolaryngology and head neck surgery, vol 1(10) no 2, aug 2013

[14]. Tariq Ashor, Endoscopic Septoplasty Versus Traditional Septoplasty, Journal of the Bahrain Medical society, Vol 22, No:2. April-Jun 2010.

[15]. Krishna K.T., Bhanu M, Krishnaveni A, Raghunath B, Jeevan P.k. Correction Of Deviated Nasal Septum: Conventional Vs Endoscopic Septoplasty. IOSR Journal of Dental and Medical Sciences. Vol- 13, pp 14-15. 
[16]. Bothra R, Mathur NN. Comparative evaluation of conventional versus endoscopic septoplasty for limited septal deviation and spur. J Laryngol Otol. 2009;123:737-741. doi: 10.1017/S0022215108004192.

[17]. D.C. Sathyki, Chyre geera, G.B. Munishwara, M. mohan. A comparative study of endoscopic septoplasty versus Conventional septoplasty. Indian j of otolaryngology \& head neck surg 2014 jun 66(2):155-161

[18]. M.Gupta, G. Motwani. Comparative study of endoscopic aided septoplasty and traditional Septoplasty in posterior nasal septal deviations. Indian j of otolaryngology \& head neck surg.vol 57.no 4, octdec 2005.

[19]. Leena J, Manish J, Chauhan A N. Conventional Septoplasty versus endoscopic Septoplasty: A comparative study. People $\mathrm{J}$ of scientific Research 2011; 4(2): 24-28.

[20]. Mahlon R,. Ven D, Paul R, Willeum E D. Endoscopic partial inferiorturbinoplasty. Otolaryngology Head and Neck Surgery 199; 121(4): 406-409.

[21]. C. Champagne, S. Ballivet de Régloix , L. Genestier, A. Crambert, O. Maurin , Y. Pons. Endoscopic vs. conventional septoplasty: A review of the literature. European Annals of Otorhinolaryngology, Head and Neck diseases 133 (2016) 43-46 